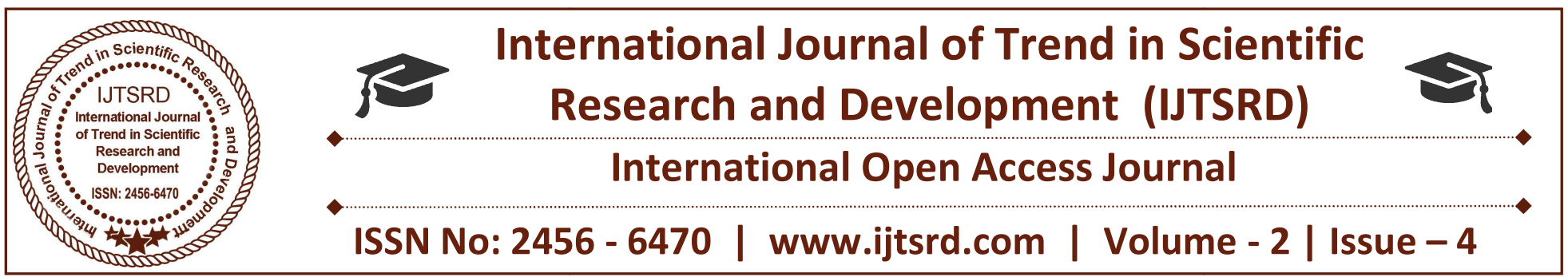

\title{
A Review on SEO: Search Engine Optimization
}

\author{
Kunal Karalkar ${ }^{1}$, Shripad Bhide ${ }^{2}$ \\ ${ }^{1}$ PG Student, ${ }^{2}$ Professor \\ Affiliated Department of (MCA), Modern college of Engineering Pune, Maharashtra, India
}

\begin{abstract}
Search engine optimization affects the presence or appearance of a website in the first page of a search engine. The visibility of a website can be paid or unpaid, but generally if a website wants to appear in the top position after an organic search then search engine optimization is the most important strategic tool to use. The whole internet marketing strategy circles around the SEO. The search engine optimization processes try to follow the / working pattern of all the search engines and more specifically try to consider the algorithm used in search engines. The SEO implementation is also based on the searching process of people.
\end{abstract}

It is very important to see and analyse the keywords that people are searching more. The SEO process for a website is required to upgrade or optimized periodically because the search engines are modifying their algorithms and trying to be more realistic in nature. There many things that affect the SEO process and that includes content of a website, the presence of the website data on social networking sites, codes used in HTML and the use of tags, backlinks etc. If a website wants to optimize its SEO and improve SERP (search engine results page) position then it has to take care of all those SEO tactics that we have discussed earlier.

Keywords: SEO; optimization; search; roles; algorithm; techniques

\section{INTRODUCTION}

SEO stands for "Search Engine Optimization." It is the process of getting traffic from the "free," "organic," "editorial" or "natural" listings on search

engines. All major search engines such as Google, Yahoo and Bing have such results, where web pages and other content such as videos or local listings are shown and ranked based on what the search engine considers most relevant to users. In very simple words - SEO is the Best way to promote your site.

Search engine optimization helps maximize the number of visitors to a particular website or page by ensuring that the site appears high on the list of organic results returned by a given search engine. Notice how Google states they are small modifications? There are lots of small changes you can make to your website or blog that will have positive results on ranking. It's the process of making changes together, in a planned and methodical manner, that drives big results.

Whenever you enter a query in a search engine and hit 'enter' you get a list of web results that contain that query term. Users normally tend to visit websites that are at the top of this list as they perceive those to be more relevant to the query. If you have ever wondered why some of these websites rank better than the others then you must know that it is because of a powerful web marketing technique called Search Engine Optimization (SEO).

SEO is a technique which helps search engines find and rank your site higher than the millions of other sites in response to a search query. SEO thus helps you get traffic from search engines.

This SEO tutorial covers all the necessary information you need to know about Search Engine Optimization - 
what is it, how does it work and differences in the ranking criteria of major search engines.

SEO is part of the broader topic of Search Engine Marketing (SEM), a term used to describe all marketing strategies for search. SEM entails both organic and paid search. With paid search, you can pay to list your website on a search engine so that your website shows up when someone types in a specific keyword or phrase. Organic and paid listings both appear on the search engine, but they are displayed in different locations on the page. So, why is it important for your business ${ }^{\text {ee }}$ website to be listed on search engines? On Google alone, there are over 694,000 searches conducted every second. I Think about that. Every second that your website is not indexed on Google, you are potentially missing out on hundreds, if not thousands of opportunities for someone to visit your website, read your content, and potentially buy your product or service. Practicing SEO basics, as well as more advanced techniques after those, can drastically improve your website's ability to rank in the search engines and get found by your potential customers. What about paid search? Yes, you can pay to have your website listed on the search engines. However, running paid search campaigns can be quite costly if you don't know what you're doing. Not to mention, about $88 \%$ of search engine users never click on paid search ads anyway. ii Because the sole purpose of a search engine is to provide you with relevant and useful information, it is in everyone's best interest (for the search engine, the searcher, and you) to ensure that your website is listed in the organic search listings. In fact, it is probably best to stay away from paid search all together until you feel you have a firm grasp on SEO and what it takes to rank organically.

\section{LITERATURE SURVEY}

\subsection{How google ranks pages?}

Search engines use their own proprietary algorithm to rank web pages to be displayed in the search results page. Search engine companies will never reveal the exact mathematical formula or algorithm that powers their search engine because it is one of their most guarded secrets. This is what Google has said about their ranking algorithm: "Traditional search engines rely heavily on how often a word appears on a Web page. Google uses PageRank to examine the entire link structure of the Web and determine which pages are most important. It then conducts hypertext- matching analysis to determine which pages are relevant to the specific search being conducted. By combining overall importance and query-specific relevance, Google is able to put the most relevant and reliable results first." As you can see from the previous quote, Google does not place great emphasis on how many times the keyword being searched appears on the web page, just like other traditional search engines, instead it uses its proprietary ranking algorithm PageRank to examine the link structure of the page to determine the relevancy and importance of web pages. The next section will cover PageRank in more detail.

Goole SEO Algorithms:

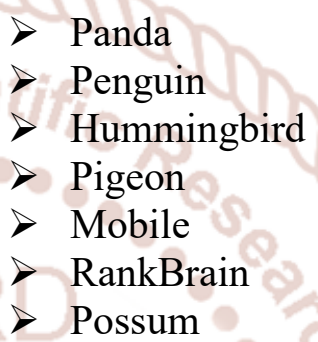

\subsection{Google Penguin vs Panda vs Hummingbird}

Search engine algorithms are based on a simple premise: searchers want an answer to their queries. For any search, there are hundreds or thousands of sites that offer a potential link or insight related to the query. As a result, search engines need to accomplish three goals:

Disqualify all the sites that aren't relevant.

$>$ Return a list of sites that are relevant.

Rank and prioritize those sites in order of importance, to identify which sites are the most relevant. Because no single factor is sufficient to provide these insights, Google and other search engines use complex algorithms that blend dozens of factors. The exact formula isn't known, but a range of topics are considered. These include:

$>$ Link authority: number of incoming links, quality of the sites, anchor text used

$>$ On page factors: such as title tags, responsive mobile design, page loading speed

$>$ Brand metrics: search volume for the brand, brand mentions, citations of brand name in connection with specific keywords

$>$ Content: quality and depth of content, frequency of new content updates, reads and shares on social media Just when you think you've grasped the specific details of Google's 
algorithm, it's important to note that changes occur all the time. By understanding the historical trends in what's changed and staying on top of how things are evolving, website owners stand the best chance of developing and implementing strategies that lead to great long-term rankings. For a more in-depth look at Search Engine ranking factors, see Moz's annual Search Ranking Factors survey.

G. S. Bedi,( March 2014), shows the importance of some techniques of Search Engine Optimization (SEO), He described previous work done on the subject of SEO, the early beginning of SEO, its goals and ideas such as White Hat SEO, Black Hat SEO, On page SEO, Off Page SEO, their benefits. Dr S. Saravanakumar, (September 2012), implied a new methodology of Search Engine Optimization (SEO) without getting sandboxed by search engines like Google, Bing and other. In the past, the algorithm was based on the quantity of back links that a site has. This process involved in implementing safe link building techniques with link velocity as its key without compromising the on page optimization. The latest algorithmic updates are taken in to consideration and the strategy is developed to rank for a keyword. By implementing this method, any organization can take advantage of the traffic from the search engines and have a good online presence. He also explained basic guidelines recommended by all the search engines for proper indexing without sandboxing. Hence even in the future; this method will not hinder the online progress of any business. Joeran Beel, discussesed the concept of academic search engine optimization (ASEO). Based on three recently conducted studies, guidelines are provided on how to optimize scholarly literature for academic search engines in general and for Google Scholar in particular. In addition, he briefly discussed the risk of researchers' illegitimately 'over - optimizing' their articles. Rajesh Singh (September 2013) discussed that extracting information is too much costly in terms of processor time. A distributed design approach is proposed in this paper. He discussed how to design a such type of search engine architecture in which processing of a search engine may be in distributed form by which the time or processing power may be reduced.

\section{BLOCK DIAGRAM/ARCHITECTURE AND APPLICATION DESCRIPTION}

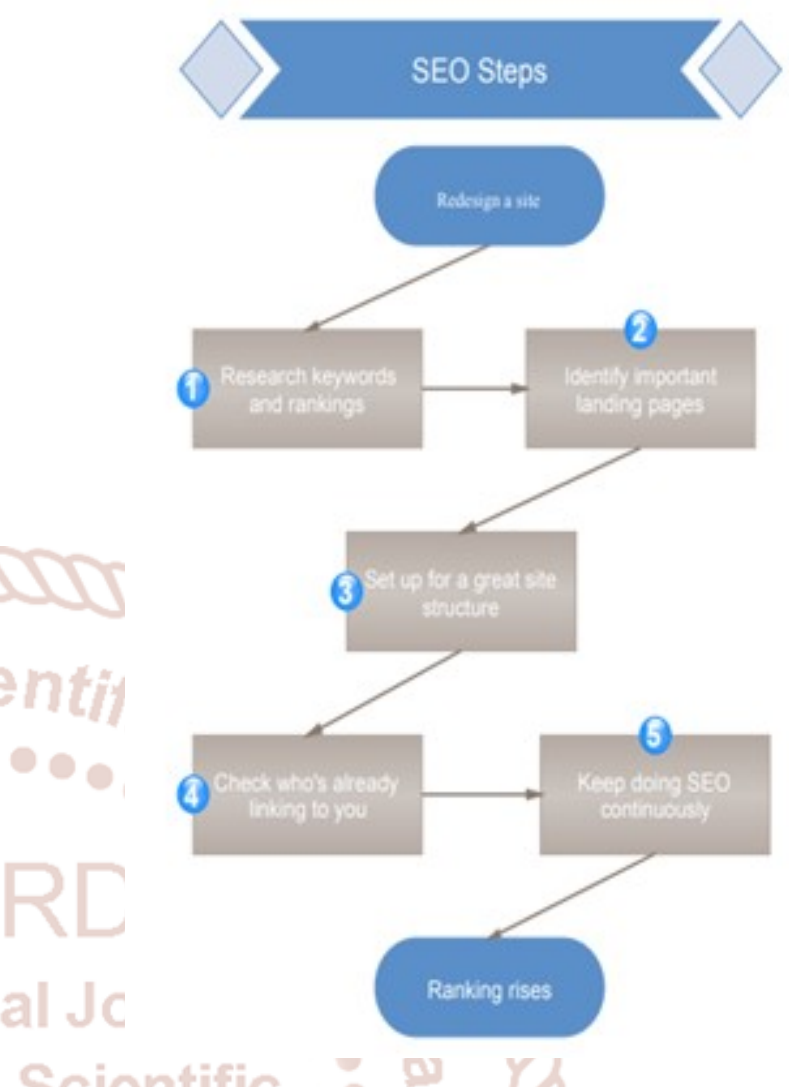

Fig 3.1 SEO stapes

\section{A. Steps of SEO}

These are 5 simple yet vital steps to do effective SEO.

\section{Research Keywords and Rankings}

Start with finding keywords that are already working for you. Three useful tools finding that data are SEMrush, Google Analytics, and Google Webmaster Tools. Make a list of most important key words. Find out which are the highest ranked pages of your website.

\section{Identify Important Landing Pages}

Before the SEO, make a list of landing pages that perform best for your site right now. Here's how you can find them. Refer to the list of important keywords you made during the previous step. Make a list of landing pages that include those keywords. And then, With Google Analytics, get a list of pages that brought you the most traffic.

\section{Set up for a Great Site Structure}

The content decides whether your site is meaningful for the users while the structure determines whether it will attract visitors. You need to make sure that 
changes you make to your site structure won't make them perform worse.

\section{$>$ Check Who's Already Linking to You}

Backlinks are the backbone of your site's SEO, and before the redesign you should fully know who's linking to you and which pages those links point to.

\section{$>$ Keep Doing SEO Continuously}

Customers' needs are changing. Others competitors are improving and more websites are being built every moment. There is no way to gain best SEO without constant improvement of the website.

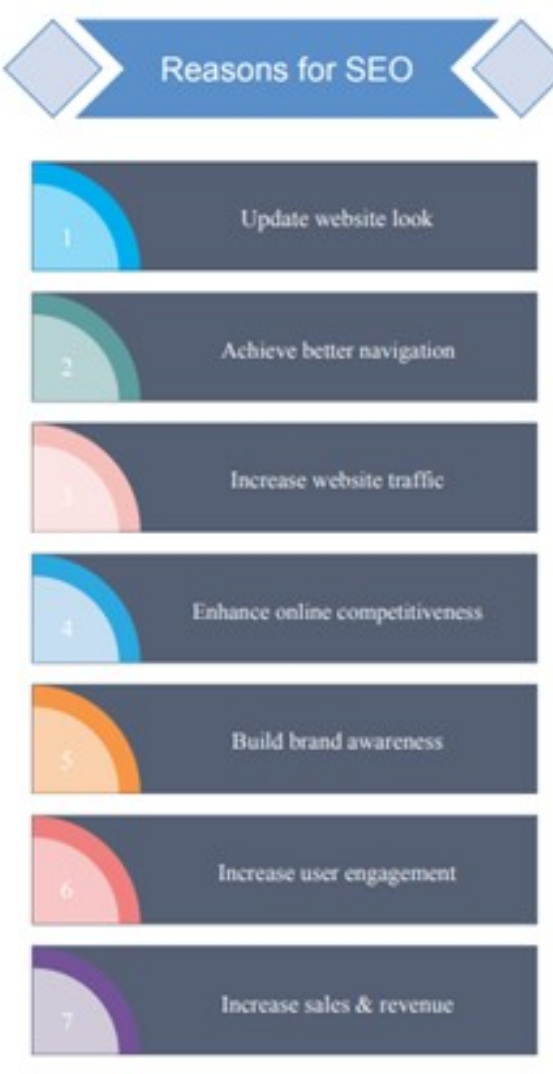

Fig 3.2 Reasons for SEO

\section{B. Reasons for SEO}

Knowing the reasons to do something helps you set up better goals. The followings are some major reasons for SEO.

Update website look. A website that looks outdated is hard to attract more visitors. So you need to update it to make it look modern.

Achieve better navigation. To help visitors gain more from your website is the basic strategy to optimize it. Better navigation will keep visitors stay in your website longer. That is why you should simplify the structure to streamline indexation, add a blog to refresh content or add links to connect related pages.

Increase website traffic. Website traffic can affect your ranking in search engines and help reinforce your status as an industry leader in your market, making you the right choice! SEO helps place your product(s) or services in front of eager consumers effectively, as well as gain a wider audience.

$>$ Enhance online competitiveness. Your competitors use SEO. You may become a laggard if you don't invest in SEO.

$>$ Build brand awareness. The website is a great channel to build brand awareness. It offers a constant way to communicate your corporate or personal image, including your products, services or logo/brand in a positive way.

Increase user engagement. SEO includes a strategy to make your website more interactive, inclusive and useful for the customers. This way, customer can quickly gain newest update of product and service information, send feedback to you anytime through your website and so on.

Increase sales \& revenue. Search Engine Optimization and marketing helps drive targeted traffic to your website while maximizing your ROI and increase online sales. Through efficient search engine marketing strategies, a search engine optimizer can help develop a steady stream of qualified traffic to your website. [D7]

\section{5 Steps to Know How SEO Works}

1. Know the On-Site Search Engine Optimization Elements

On-site optimization is probably the most imperative components of how SEO Works on your website. You may have found experts who talk a considerable measure about link building (which I will discuss later), yet link building without befitting on-Site Search Engine Optimization, will not be as compelling. Let us delve into minimum on-site SEO components you ought to put on each of your site's main pages, including home page, landing pages, etc.

\section{On-Site SEO Elements to know How SEO Works}

a. Role of Title Tag- The title tag updates search engines what truly matters to the page. It ought to be 70 characters or less and incorporate your business or brand name and related keywords that identify with that particular page as it were. This tag is put between 
the $<$ HEAD $></$ HEAD $>$ labels close to the top point of the HTML code for a particular page.

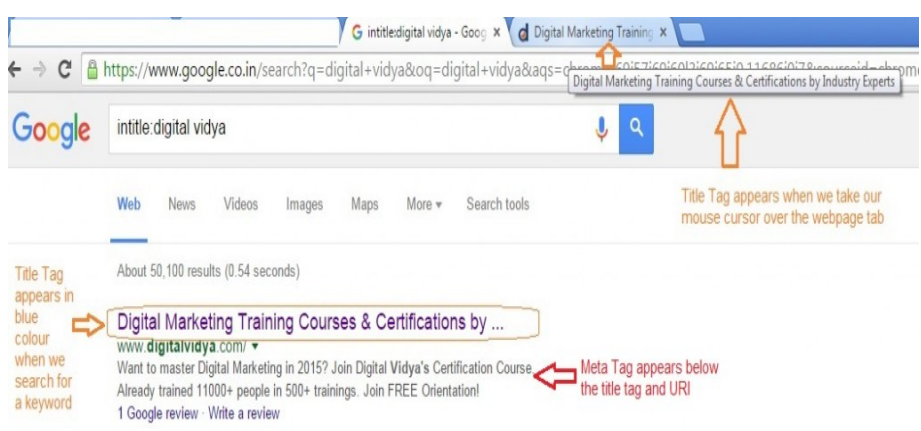

Fig 3.3 SEO title tag

b. Role of Meta Description- The Meta description of your site gives search engines somewhat more knowledge into what truly matters to your page. There may still be a civil argument about whether Meta description can help with keyword rankings. In any case, you need to compose your Meta description in view of your target audiences that incorporates the page's fundamental keywords, as this would be shown in search results of search engines.

Title Tag and Meta Description in Search Results

\begin{abstract}
SEO Training - Digital Vidya
www.digitalvidya.com/seo-training/ v

$\star \star \star \star \star \star$ Rating: 3.5/4 - 301 reviews

Want to master Search Engine Optimization (SEO) in 2015? Join SEO Certification

Course. Trained 11000+ People across 500+ Trainings since 2009.

Professional SEO Training Institute in Pune - SEO Course ...
\end{abstract}

Fig 3.4 SEO title and meta description

The above picture indicates how search results have title tag and Meta description appears in Google search results. To know what Search Engine Optimization is and how SEO works, it is important to know right use of title tag and Meta description. You can see that the keywords looked by a client (for this situation, the keyword was SEO) are emboldened by Google in both the title tag and the Meta description. This is the reason you need to utilize your business or brand name and keywords in both the title and Meta description - it helps your query items emerge to the searcher when they are seeking those terms.

c. Role of WordPress use- On the off chance that you utilize WordPress, it is going to be more helpful. Including title labels and Meta description to your pages is simple in WP by utilizing free plugins such as- All in One SEO, SEO by Yoast, Scribe SEO and Platinum SEO.

Along with title tags and the Meta descriptions, which are the most essential SEO components, there are some others as well. If you wish to know what SEO is and how it works - make sure to comprehend and fuse the below given on site elements as well into your site's page content for effective search engine optimization-

Some other on-Site Elements to understand how to Work in SEO

a. Role of Header Tags - Generally, an SEO friendly blog entry uses three distinct levels of HTML header labels that help break the content into different section and additionally let search engines find out about what really matters to each segment of a content.

The $<\mathrm{H} 1></ \mathrm{H} 1>$ labels encompass the post title there ought to just be one arrangement of $<\mathrm{H} 1></ \mathrm{H} 1>$ tags for each page.

The $<\mathrm{H} 2></ \mathrm{H} 2>$ and $<\mathrm{H} 3></ \mathrm{H} 3>$ tags encompass subheadings on the page - there can be numerous occasions of both. Utilizing header labels helps both site-visitors and web search engines separate your content.

b. Role of Internal Links - Internal link building is not only the opposite of external links. You can influence web crawlers take in more about your site by internally connecting to different pages on your site, via links within your own content. For instance, this blog uses internal links when connecting to different posts on the Digital Vidya blogs.

c. Role of Emboldened Text - You would prefer not to get excessively insane with this one, however, at times bolding a choice of content to stand out enough to be noticed can likewise help search engines recognize other imperative data and keyword related data in the content of a particular page.

d. Role of Image Name and ALT Tags - If you utilize pictures on your site, you ought to consider befitting keywords for both the picture name and the alt tag. This aid search engines discover great pictures for their image-search for any specific keywords. 


\section{LEARN OFF-SITE SEARCH ENGINE OPTIMIZATION (OTHERWISE KNOWN AS LINK BUILDING)}

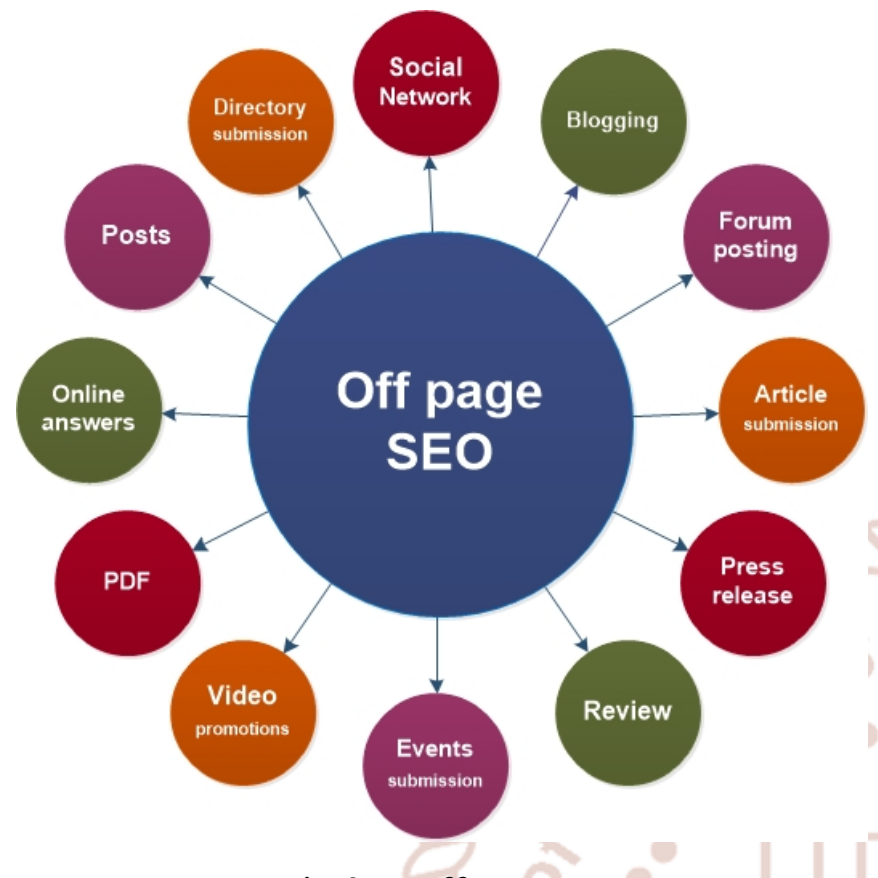

Fig 3.5 Off page SEO

Link Building is presumably a standout amongst the most discussed SEO topics covered in "How SEO Works" Guides. The fundamental objective of thirdparty referencing is to get different sites to link to yours to increase traffic and search ranking.

In the event that you consider positioning at the top results of SERPs as your SEO challenge, then link building is like votes, saying your site should be positioned at top spots. Having befitting links with Keyword Anchor text will help you rank particularly for the keywords that are connected via link building.

So how would you get links? There are parts and heaps of approaches to do it rightly - some great, and some not all that great. In the event that you read enough about external link building, you will hear eventually around three sorts of link building systems-

a. Organic Links - These are the natural links that you do not need to request, and that is why they are the best kind of links. Particularly in the event that you can get them on sites with high authority scores, they would be more effective.

b. Whitehat Links - This essentially remains for Quality Link Building Services that you ought to make progress toward. c. Blackhat Links - These are the spammy links, which are of low quality and the kind you ought to stay away from.

Most of the sites experience considerable difficulties generating enough natural links to increase their rankings in search engines. This is the reason off-site optimization is such a well-known administration. Nevertheless, you can begin your off-site optimization by paying heed upon following practices-

Try to submitting guest blog entries to prominent online journals and popular blogs in your industry. By and large, you will get a link related to your site in top or bottom of your post. You may also create local search profiles and online networking profiles on different social media channels. While the external links do not generally number towards search rankings in SERPs, they can pull in clicks, which will produce more traffic to your site.

Try to ask related organizations/businesses/entrepreneurs to check whether they will like to link to you. A decent approach to do this is to check whether the organizations you work with, have link pages on their site for accomplices, sellers, vendors, partners and so forth. This is how Google SEO works more effectively by using result-oriented link building.

You can also submit your site to pertinent industry directories or, you can purchase advertising. For instance, anybody in the Digital Marketing Training could get listings with a link back to their site on Digital Marketing Course, Digital Marketing Career, and other comparable sites. Try to avoid low-quality directories that have nothing to do with your industry. You should also avoid a site that connects to shady sites in the pharmaceutical, adult or casino businesses.

Creating content that is Link-Worthy is another way how SEO works in a link-oriented fashion. Infographics are an extraordinary illustration you can make an excellent image highlighting imperative data and enable others to utilize the infographic on their site in return for linking back to your site as a credit.

For more information about correct link building practices, don't miss our post on Techniques for Link Building 
3. Content is Important for both- Site Visitors \& Search Engines

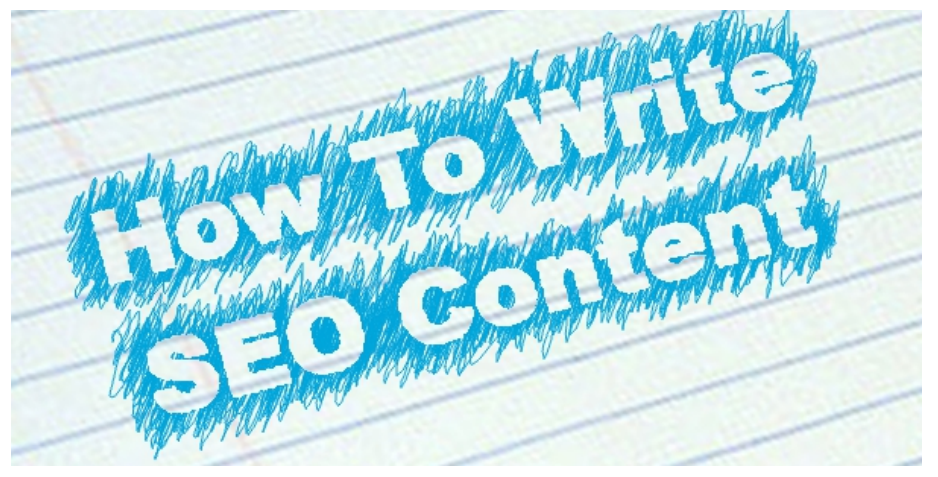

Fig 3.6 how to write SEO content

$>$ In the event that you stay aware of the most recent internet marketing news, then you'd have likely learned a lot about content marketing and importance of highly engaging content. Having interactive, unique and engaging content is extraordinary for bot-h your site guests and search engines.

$>$ The more effective, informative and interesting content you have, the more probable that your guests will stick around on your site. Furthermore, it influences search engines to put a greater number of your site's pages in their search indexes.

$>$ The best way to satisfying both visitors and search engines is to have quality content on your site. Different kinds of quality content that you may offer on your site are-

\section{Blog Posts}

2. Industry Articles

\section{E-Books}

4. Tutorials and How to Guides

5. Infographics

6. Slides

7. Videos

\section{Podcasts, etc.}

Composing quality content for your site can be a tremendous venture, yet it is justified despite all the troubles. Web indexes will love it, and guests will value it so much that they will share it via web-based social networking channels, prompting considerably more guests to your sites.
To know how SEO works, it is must to know how to use content marketing in SEO-friendly manner. To do so, you may begin by just making blog posts on your site, and as your audiences develop, you can grow your content stock to other kinds of content that suit your business.

$>$ To take in more, go through our Webinar Recording on Content Marketing

\section{Learn How Google SEO Works via Google+}

If you want to know how Google SEO works, and wish to dominate Google's SERPs, then you ought to join Googlet. Google's own informal organization can help you rank better in list items for individuals you are associated with. For instance, when I'm signed into Google+ and scan for 'SEO' in Google search, I get below-given five search results that are also customized as per my friend list (a little person icon is there for 2 of my friends).

In another example, when I'm not signed into Google+, two customized results of my friends are not in the top five search results for same keyword i.e. SEO.

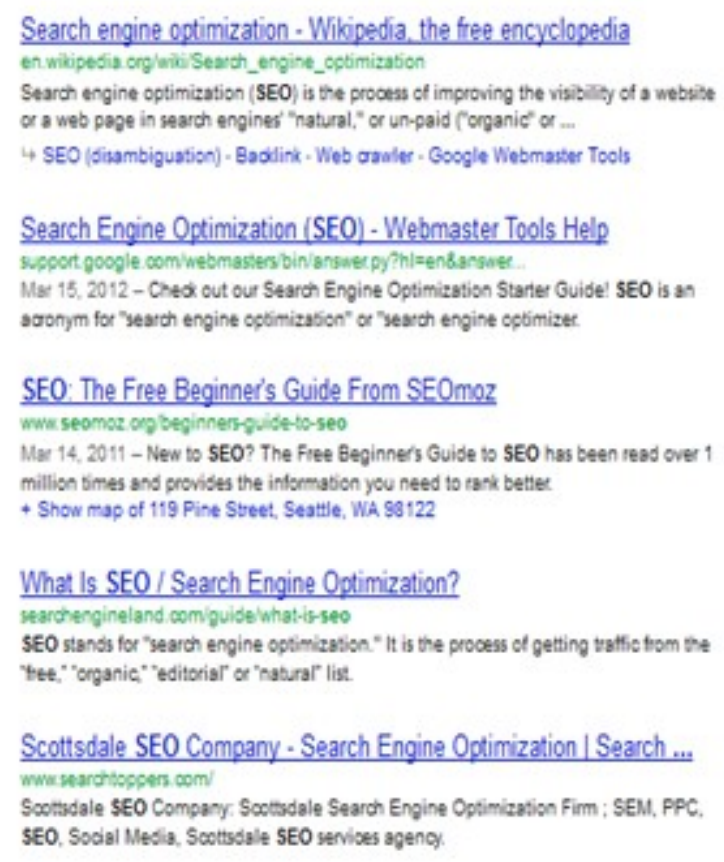

Figure 3.7 Result of SEO

\section{Learn how SEO Algorithm works}

To use Google+ for improving your search ranking, you need to create a Google+ profile and business page.

Recommend the site you need to rank well in SERPs by giving it $\mathrm{a}+1$. 
$>$ Share the site on your profile as status update and link it to your profile details under suggested sites.

Fill out your profile details accurately, check your settings, and ensure that your profile data is public.

$>$ Share other fascinating reports, interesting news on your profile so it does not look excessively self-oriented.

$>$ Start associating with individuals who you need to see your site in SERPs.

$>$ Utilize the search box given on Google+ to discover individuals to connect with. You should add them to your circles and it is almost sure that most of them will add you back.

$>$ Actually, the more famous you are on Google+, the more probable you are to influence customized search lists with the individuals who are tailing you. Henceforth, you should explore Google+ community to its fullest degree to receive the great rewards.

\section{Monitor your Search Engine Optimization Campaigns}

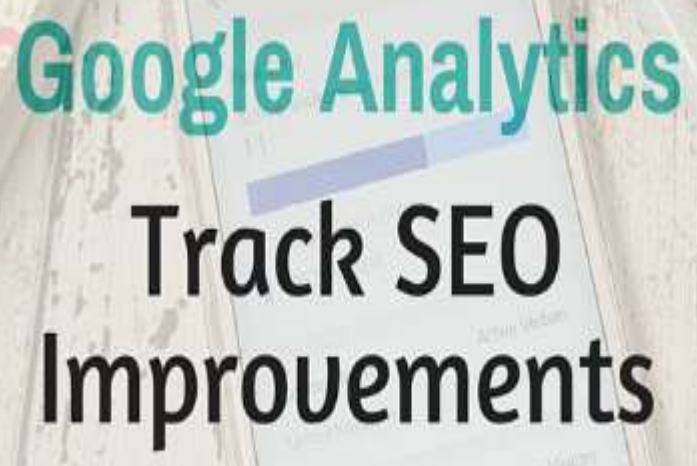

Fig 3.8 Track SEO improvements with Google Analytics

The last point of every "What is SEO and How does it Work Guide" is the tips to track or monitor your SEO campaigns and related outcomes. The two most critical tools you can use to screen these outcomes are-

$>$ Google Analytics- To know how SEO works, you need to know how to use Google Analytics to track visitors of your site. Specifically, screen your organic traffic sources to perceive what keywords individuals are utilizing to discover your site in their queries. By setting up objectives, you can see which keywords prompt visits where guests do what you need them to do on your site.
This aids you realize what keywords you ought to focus in your SEO campaign.

Authority Labs- You can utilize this tool to track keyword rankings for your site so you can check whether they are climbing in search results.

\section{TOOLS AND TECHNIQUES}

\section{A. Google Trends}

Google Trends is a go-to keyword tool. You can see how search queries change over time when people search for your keyword and compare different words or phrases to see which is best.

Let's say you run a hardware store and you want to ramp up sales of shovels this winter. When people search for a shovel online, do they search for winter shovel or snow shovel? Compare the two using Google Trends. Here's what you'll see:

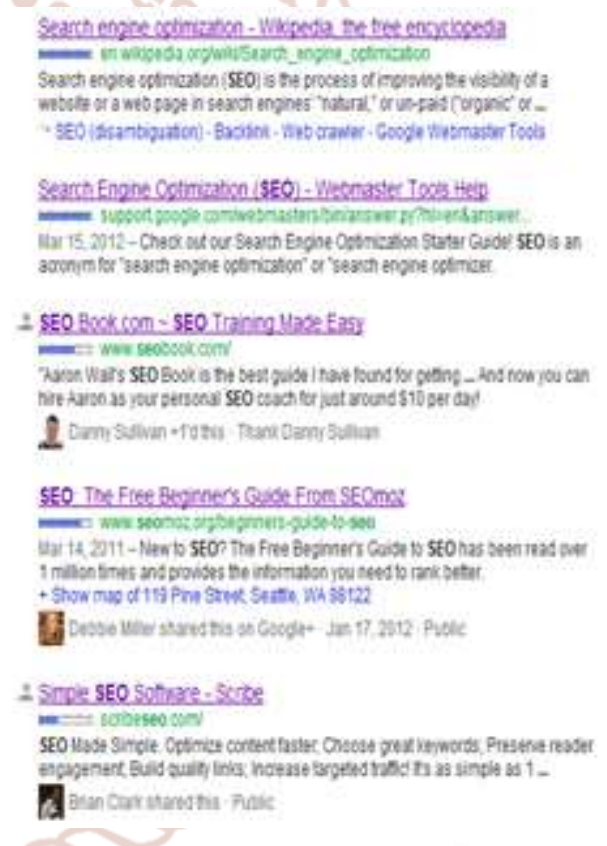

Fig 3.9 Goole Trends

According to the chart, people search for snow shovel more frequently than winter shovel. The chart also shows you when people search for the term. In this case, it's no surprise that the winter months are when this term is most popular.

You can also take a look at a regional breakdown that shows you where the search terms are most popular.

With this knowledge, you can use the phrase 'show shovel' on your website and blog posts to increase traffic. 


\section{B. BROWSEO}

This tool shows you how a search engine sees your site. It strips your site down to a base level, without any fancy fonts, headers or images, and displays relevant SEO information. By looking at your site this way, you can see what needs improvement. All you have to do is enter your URL into the site, no additional downloads necessary.

\section{Screaming Frog}

What SEO problems does your website face? Aren't sure? Turn to Screaming Frog. Free for the first 500 URLs, this tool crawls your site looking for SEO roadblocks and provides a report of problem areas.

The tool looks for broken links, missing metadata, oversized files and pictures, duplicate pages and internal links, just to name a few. Think of it as an SEO audit. Use the results to improve your site and SEO.

\section{GTmetrix}

How fast does your website load? Do you have a page or two on your site that takes too long to come up? Sluggish page speed can hinder SEO. Site speed does play a role in search engine rankings, so you'll want to double check the speed of your site with GTmetrix.

Just enter your URL into the site and you'll get a page speed score and a list of ways to improve it. For example, it might suggest resizing images to improve load times.

\section{E. Rank Checker}

Where does your website land in search engine results? Find out with Rank Checker. This tool will show you where your site shows up and give you tips to improve it.

You can install a button on your toolbar so you have easy access to this information whenever you'd like. It will take time to move your site up the ranks, but with this tool you can keep an eye on where you stand.

\section{F. Responsive Design Test}

How does your site look on a smartphone? Search engines give preferential treatment to websites that look great on all devices, no matter their size or orientation.

To make sure your website looks sharp on every device, use a responsive website design. This design adapts to every device, so you don't need to create multiple sites.

Not sure if you have a responsive design? Put your website into the Responsive Design Test to find out. If you don't have a responsive design, consider updating your site or getting help from professional designers at our partner Deluxe.

\section{ADVANTAGES AND DISADVANTAGES}

\section{ADVANTAGES}

It's free: sort of. SEO doesn't rely on adverts or paid media; all the tactics require is time. Obviously, for many organisations that may mean paying for someone's time, but it's still, in theory, providing a continuous flow of free traffic.

People trust search results: if you manage to organically appear high in search results then you'll likely experience higher conversation rates and better ROI. Search becomes the \#1 driver of traffic for many sites and leads from search can have a high $14.6 \%$ close rate. There are huge rewards to reap, and because of the trust it can also be great for your brand integrity

Searchers are often ready to buy: if you focus your SEO efforts on search terms specific to your product, chances are that your customer is a real prospect. Someone who searches for "PR agency in UK" - they are probably looking to talk to someone and make a decision. This means you'll be using your time bringing in potential, relevant, customers.

\section{Gives a higher brand integrity:}

Individuals assume that getting in the top of Google's search results page, by doing SEO, will turn your site into THE brand name. You're the person the contenders need to beat. The further back you are in rankings on Google the more individuals are suspicious about your site. Advertisements can regularly be viewed as irritating and many individuals have promotion blockers introduced on their programs. Longer articles, between 1,200 to 1,500 words, perform better in search, on average, Laetsch says. "It's significantly different than it was two or three years ago, when 300 words was a pretty long page. Longer articles are getting more traffic, and they're ranking higher in SEO, especially for competitive terms. The changes that Google is making, and the reason they're making these changes, is to make sure they're sending traffic to pages that delight humans." 


\section{DISADVANTAGES}

It takes time: changes can take weeks, or months to show. Google and other search engines are looking for reliable content and having one blog post will not be enough to shoot to the top of results. It'll be a while before you see improvements, and thus a ROI. SEO takes investment and patience. On the plus side, it also means that if you pause activity it will take a while for you to slip in results as well. Be aware if an agency says they can deliver quick results be suspicious. They may be using so-called "black hat" tactics that can damage your website in the long term.

$>$ There's no guarantee: there are so many external factors around competition and search trends, and we will never know 100\% how each search engine's algorithms work. Therefore, it's very difficult to ensure results. To improve your chances, you should be prepared to focus on niche markets and product areas - the less competition the easier it will be to make an impact.

$>$ Keeping up with the search engines themselves: Google et al are constantly trying to change their algorithms to ensure that a) nobody is cheating the system, and b) they are serving the best websites for the search terms. This can include technical aspects, so you need to constantly be looking for updates and ensuring your site is meeting any new requirements. For example, you will be heavily penalised for not having a mobile optimised site.

\section{CONCLUSION}

To get the best search engine visibility, web designers should follow the Five Basic Rules of Web Design, which state that a web site should be:

$>$ Easy to read

$>$ Easy to navigate

$>$ Easy to find

$>$ Consistent in layout and design

$>$ Quick to download

By following these rules, you are building your web site to satisfy your target audience. The added benefit of following these rules is that both directory editors and search engines are looking for these same characteristics.

The following design components help form the foundation of an effective search engine marketing program:
$>$ Text component

$>$ Link component

$>$ Popularity component

Web pages that contain the words that your target audience is typing into search queries generally have greater search engine visibility than pages that contain little or no keywords. The way your web pages are linked to each other also affects your site's search engine visibility. If search engine spiders can find your pages quickly and easily, your site has a much better chance of appearing at the top of search results.

If two web sites have the same text component and link component "weights," the site that end users click the most will usually rank higher. Sometimes, a popular web site will consistently rank higher than sites that use plenty of keywords. Therefore, building a site that appeals to both directory editors and your target audience is very important for maximum search engine visibility.

\section{ACKNOWLEGEMENT}

I take this opportunity to sincerely thank my teacher, Prof. Mr. Shripad Bhide for her timely suggestion and invaluable guidance during preparation of this paper. She is the one who gave me confidence for publishing this paper.

\section{REFERENCES}

\section{Links}

\section{A] Abstract}

1] http://www.collegelib.com/t-search-engineoptimization-seo-seminar-abstract-report.html

\section{B] Introduction}

http://www.insivia.com/wpcontent/uploads/2013/02/InsiviaSeminarKeyTakeway s.pdf

3] https://www.web-savvymarketing.com/2016/04/introduction-search-engineoptimization/

4] https://cdn2.hubspot.net/hub/53/file-13204607$\mathrm{pdf} /$ docs/introduction-to-seo-ebook.pdf

\section{C] Literature Survey}


5] https://searchengineland.com/8-major-googlealgorithm-updates-explained-282627

6] https://www.onlinejournal.in/IJIRV2I8/140.pdf

\section{D] Block diagram/Architecture and Application Description}

7] https://www.edrawsoft.com/seo-flowchart.php

8] https://www.digitalvidya.com/blog/how-seo-works/

\section{E] Advantages and Disadvantages}

9] https://www.seohorizon.com/seo-benefitsdisadvantages-explained/\#.Wqd1JehubIU

10] http://www.digitalstorey.com/blog/2017/1/30/theadvantages-and-disadvantages-of-seo

\section{F] Tools and Techniques}

11] https://www.verticalresponse.com/blog/6-freeseo-tools-to-boost-your-search-engine- rankings/

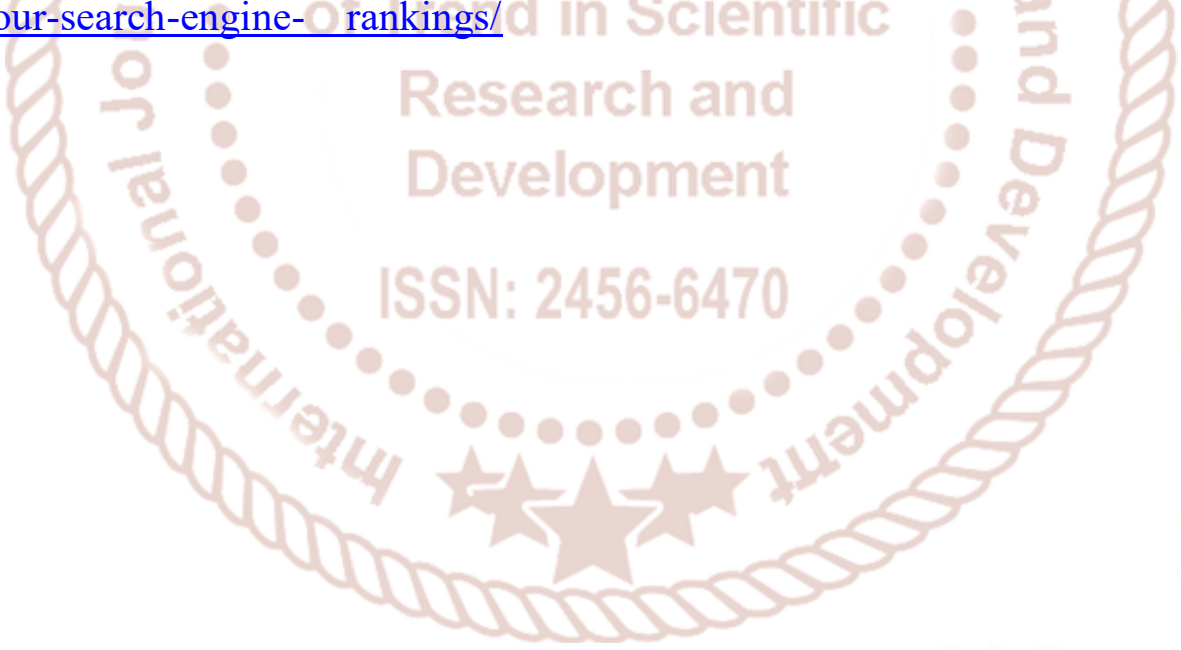

